\title{
PEMBERDAYAAN PASIEN DENGAN PENDEKATAN SELF HELP GROUP TERHADAP PERUBAHAN MEKANISME KOPING PADA PASIEN GANGGUAN JIWA SKIZOPRENIA DI RSJD DR ARIF Z SURAKARTA
}

\author{
Endang Caturini Sulistyowati, Dwi Sulistyowati \\ Poltekkes Kemenkes Surakarta Jurusan Keperawatan
}

\begin{abstract}
Background: Schizophrenia is one of the most common forms of mental disorders in Indonesia. Effective treatments for mental disorders are coming from themselves (WHO, 2018), for some mental disorders require empowerment, one of which is Self Help Group therapy. Self Help Group aims to develop empathy among fellow group members where fellow group members provide mutual support to form adaptive coping. This study aims to determine the effect of empowering patients with the Self Help Group approach to coping mechanisms in patients with schizophrenic mental disorders. Method: The research is quasi experiment with a pre-post test design with control group design. Data was taken before and after the administration of self-help intervention groups in schizophrenia in the intervention group. The number of samples is 66 clients divided by 2, namely 33 respondents for the intervention group and 33 respondents for the control group. This study measured coping mechanism. The research instrument used a coping mechanism questionnaire. Data were analyzed using dependent t-test, independent multiple linear regression t-test. Results: The study prove that there are significant differences in the coping mechanism before and after giving Self Help Group ( $p$ value, 0.000). Self Help Group if implemented by the patient has the opportunity to improve coping mechanisms by $20.1 \%$ and is expected to improve the coping mechanism by 4.909 points. Conclusion: The Self Help Group used for interventions is considered effective to increase coping skills.
\end{abstract}

Keywords: Schizoprenia, Self Help Group, Coping Mechanism

\section{PENDAHULUAN}

Skizofrenia merupakan salah satu bentuk gangguan jiwa yang paling banyak ditemukan di Indonesia. Jumlah pasien dengan gangguan jiwa di Indonesia terus bertambah. Berdasarkan hasil Riskesdas prevalensi gangguan jiwa berat, seperti skizofrenia di Indonesia sebanyak 1,7 per 1.000 penduduk (Riskesdas, 2013) dan meningkat mencapai sebanyak 7,0 per 1.000 Riskesdas (2018). Demikian juga terjadi peningkatan pasien gangguan jiwa yang dirawat di RSDJ Dr Arif Z selama 3 tahun ini dari tahun 2012-2016, berjumlah 4.001 orang meningkat menjadi 4.545 orang pasien menderita gangguan jiwa dengan rincian 2.817 rawat inap dan 1.728 rawat jalan (MR RSDJ Dr Arif Z Surakarta, 2017).

Pengobatan yang efektif untuk gangguan jiwa datang dari mereka sendiri (WHO, 2018), untuk itu gangguan jiwa membutukan pemberdayaan salah satunya dengan terapi Self Help Group, yang di Indonesia sampai saat ini masih belum berkembang. Self help group merupakan suatu kelompok dimana saling tiap anggota memiliki keinginan yang sama 
untuk mengatasi gangguan mental atau meningkatkan tingkat kesejahteraan kognitif atau emosional sesama anggota kelompok (Wikipedia, 2018).

Self help group bertujuan untuk mengembangkan empathy diantara sesama anggota kelompok dimana sesama anggota kelompok saling memberikan penguatan untuk membentuk koping yang adaptif. Self help group pada pasien gangguan jiwa perlu dilakukan untuk membantu mengatasi permasalahannya yang diselesaikan bersama dalam kelompok. Peneliti mengangkat topik yang berjudul pemberdayaan pasien dengan pendekatan Self Help Group terhadap perubahan mekanisme koping pada pasien gangguan jiwa skizoprenia di RSJD Dr Arif Z Surakarta. Penelitian ini bertujuan untuk mengetahui pengaruh pemberdayaaan pasien dengan pendekatan Self Help Group terhadap koping mekanisme pada pasien gangguan jiwa Skizoprenia

\section{METODE PENELITIAN}

Metode penelitian ini menggunakan "quasi experimental prepost test with control group" (Sugiyono, 2010). Pengelompokan anggota sampel pada kelompok eksperimen dan kelompok kontrol tidak dilakukan secara random atau acak sehingga rancangan ini sering disebut dengan Non Randomized Control Group Pretest Postest Design (Notoatmojo, 2010), sebagai intervansi berupa Self Help Group. Penelitian dilakukan untuk mengetahui perubahan mekanisme koping pada pasien skizofrenia sebelum dan sesudah diberikan perlakuan berupa Self Help Group.

Peneliti melakukan pengukuran sebelum perlakuan dan sesudah perlakuan dengan kuesioner. Peneliti membagi menjadi dua kelompok yaitu kelompok intervensi dan kelompok kontrol. Kelompok intervensi adalah kelompok yang mendapat perlakuan yaitu Self Help Group sedangkan kelompok kontrol adalah kelompok pembanding yang tidak mendapatkan perlakuan Self Help Group di Rumah Sakit Jiwa Daerah Surakarta. Data diambil sebelum dan sesudah pemberian intervensi self help groups pasien skizofrenia kelompok intervensi. Jumlah sampel sebanyak 66 klien dibagi 2 yaitu 33 responden untuk kelompok intervensi dan 33 responden untuk kelompok kontrol. Penelitian ini mengukur mekanisme koping. Instrumen penelitian dengan mengunakan kuesioner mekanisme koping. Data dianalisis menggunakan analisis bivariat dan analisis multivariat. Analisis bivariat dua uji rata-rata yaitu membandingkan ratarata dari dua kelompok (Hastono, 2007) dengan uji $t$ independen, sedangkan uji $t$ analisis bivariat digunakan untuk membuktikan hipotesis bahwa pasien dengan skizofrenia yang mendapatkan Self Help Group memiliki mekanisme koping yang lebih tinggi dibandingkan dengan pasien yang tidak mendapatkan Self Help Group. Sedangkan analisis multivariat digunakan untuk membuktikan bahwa ada karakteristik pasien sebagai faktor yang berkontribusi terhadap mekanisme koping pasien menggunakan regresi linier ganda

\section{HASIL PENELITIAN}

Analisis mekanisme koping pasien sesudah mendapatkan SHG pada pasien gangguan jiwa dengan skizofrenia dilakukan untuk melihat perbedaan mekanisme koping pasien antara kelompok intervensi dan kontrol. Analisis 
dilakuka dengan menggunakan uji $t$ independen, dengan hasil uji analisis terangkum dalam tabel 1 .

Tabel 1. Hasil uji t independen tentang perbedaan mekanisme koping antara kelompok kontrol dan intervensi, sebelum dan sesudah intervensi SHG

\begin{tabular}{llclll}
\hline Kelompok & $\mathbf{N}$ & Mean & SD & T & P \\
\hline Kontrol & 33 & 1,12 & 5.128 &.-4.008 & 0.000 \\
Intervensi SHG & 33 & 6,03 & 4,818 & & \\
\cline { 2 - 3 } & 66 & & & & \\
\hline
\end{tabular}

Hasil analisis menggunakan uji $t$ independen menunjukan terdapat perbedaan yang secara statistik signifikan $(\mathrm{p}=0,05)$, tentang mekanisme koping pasien antara kelompok intervensi dan kontrol. Rata-rata peningkatan mekanisme koping pasien pada kelompok intervensi (mean 6,03) lebih tinggi dari pada kelompok kontrol (mean 1,12) dengan $\mathrm{p}$ $<0.05$.

Analisis untuk membuktikan bahwa ada karakteristik pasien sebagai faktor yang berkontribusi terhadap mekanisme koping pasien menggunakan 2 model analisis regresi linier ganda, Model I menghubungkan intervensi Self Help Group saja dengan mekanisme koping pasien tanpa mengontrol variabel perancu. Model II menghubungkan intervensi Self Help Group dan mekanisme koping pasien dengan mengendalikan 5 variabel perancu yaitu umur, status perkawinan, pendidikan, pekerjaan, frekuensi dirawat, dan mekanisme koping pasien sebelum intervensi.
Tabel 2. Hasil analisis regresi linier ganda tentang intervensi Self Help Group terhadap mekanisme koping pasien dengan tanpa mengontrol pengaruh umur, status perkawinan, pendidikan, pekerjaan, frekuensi dirawat.

\begin{tabular}{|c|c|c|c|c|c|c|c|c|}
\hline \multirow[t]{3}{*}{ Variabel } & \multicolumn{4}{|c|}{ Model I } & \multicolumn{4}{|c|}{ Model II } \\
\hline & \multirow{2}{*}{$\begin{array}{l}\text { Koef } \\
\text { Regre } \\
\text { si } \\
\text { B }\end{array}$} & \multicolumn{2}{|c|}{ CI $95 \%$} & \multirow[b]{2}{*}{$\mathrm{P}$} & \multirow{2}{*}{$\begin{array}{l}\text { Koef } \\
\text { Regre } \\
\text { si } \\
\text { B }\end{array}$} & \multicolumn{2}{|c|}{ CI $95 \%$} & \multirow[b]{2}{*}{$\mathrm{p}$} \\
\hline & & $\begin{array}{l}\text { Batas } \\
\text { bawah }\end{array}$ & $\begin{array}{l}\text { Bata } \\
\text { s } \\
\text { atas }\end{array}$ & & & $\begin{array}{l}\text { Batas } \\
\text { Bawa } \\
\mathrm{h}\end{array}$ & $\begin{array}{c}\text { Batas } \\
\text { atas }\end{array}$ & \\
\hline & & - & & & 10 , & 2,93 & 17,9 & , 00 \\
\hline & & 0 . & & & 422 & 6 & 08 & 7 \\
\hline & 1,12 & 60 & 2,85 & 0.20 & & & & \\
\hline \multirow[t]{2}{*}{ Konstanta } & 1 & 9 & 2 & 0 & & & & \\
\hline & & & & & 4,7 & 2,45 & 7,07 &, 00 \\
\hline Status & 4,90 & 2,46 & & 0.00 & 63 & 4 & 2 & 0 \\
\hline \multirow[t]{3}{*}{ Interv } & 9 & 2 & 7,356 & 0 & & & & \\
\hline & & & & & - & - & ,068 &, 25 \\
\hline & & & & & ,09 &, 251 & & 7 \\
\hline \multirow[t]{2}{*}{ Umur } & & & & & 1 & & & \\
\hline & & & & & - & - & - &, 00 \\
\hline Jenis & & & & & 4,5 & 7,19 & 1,84 & 1 \\
\hline \multirow[t]{3}{*}{ kelamin } & & & & & 18 & 2 & 5 & \\
\hline & & & & & - & - & 2,32 &, 83 \\
\hline & & & & & ,26 & 2,86 & 9 & 6 \\
\hline \multirow[t]{3}{*}{ Pekerjaan } & & & & & 9 & 8 & & \\
\hline & & & & & ,34 & - & 1,69 & ,61 \\
\hline & & & & & 0 & 1,01 & 3 & 7 \\
\hline \multirow[t]{2}{*}{ Pendidikan } & & & & & & 3 & & \\
\hline & & & & & ,38 & - & 2,99 &, 76 \\
\hline Status & & & & & 9 & 2,22 & 9 & 7 \\
\hline kawin & & & & & & 1 & & \\
\hline Frekwensi & & & & &, 15 & - & ,391 &, 21 \\
\hline dirawat & & & & & 0 & ,090 & & 6 \\
\hline \multirow[t]{2}{*}{ N respd } & 66 & & & & 66 & & & \\
\hline & 20,1 & & & & 38,5 & & & \\
\hline \multirow{2}{*}{ Adjusted $R^{2}$} & $\%$ & & & & $\%$ & & & \\
\hline & 0.00 & & & & 0.00 & & & \\
\hline $\mathbf{P}$ & 0 & & & & 0 & & & \\
\hline
\end{tabular}

Hasil analisis menggunakan regresi linier ganda, berdasarkan Model I dapat disimpulkan bahwa intervensi Self Help Group efektif untuk meningkatkan mekanisme koping pasien. Pasien yang mendapatkann intervensi Self Help Group, rata-rata meningkatkan mekanisme koping pasien dengan 4,909 poin lebih tinggi dari pada pasien yang tidak mendapatkan intervensi Self Help Group dan perbedaan tersebut secara statistik signifikan $(b=4,909$; CI 95\% 2,462-7,356; $\mathrm{p}$ value 0,000). Hasil analisis menunjukkan, ternyata tidak ada 
perbedaan koefesien regresi b untuk intervensi SHG antara model I dan model II, yaitu sebesar $(4,909-4,763) / 4,909=$ $14,6 \%<(10 \%-20 \%)$. Jadi variabel perancu yang dimasukkan ke dalam model II ternyata tidak merancukan estimasi efek dari intervensi SHG sehingga estimasi efek intervensi SHG yang digunakan adalah hasil perhitungan model I. Adjusted $R^{2} \quad$ sebesar $20.1 \%$ pada model I menunjukkan intervensi SHG mampu meningkatkan mekanisme koping pasien sebesar $38.5 \%$

\section{PEMBAHASAN}

Hasil ini sejalan dengan pernyataan dalam Wikipidia (2018), bahwa Self Help Group mengubah anggota dalam perspektif diri mereka sendiri, belajar strategi koping baru, latihan perilaku. Dikuatkan dengan penelitian Zachariades, F. K. (2000) yang menyatakan bahwa koping berhubungan dengan masalah kesehatan dan peristiwa stres sebelumnya. Keterampilan koping lebih efektif dikembangkan sebagai yang mana paling fungsional, dapat berkontribusi secara signifikan dalam hal memediasi hasil penyakit, penyesuaian dan proses pemulihan

Ini sejalan dengan pernyataan dalam penelitian Budd, M. (2004) bahwa Self Help Group sangat penting dalam memberikan dukungan untuk orangorang yang mengalami tekanan mental. Orang-orang yang menghadiri Self Help Group sering menyebut mereka sebagai life-line/ garis hidup. Anggota Self Help Group merasa diterima dan tidak lagi sendirian dengan kesusahan dan pengalaman mereka. Demikian juga mereka sendiri sering merasa lebih berdaya sebagai individu dan sebagai kolektif dalam komunitas lokal mereka.
Demikian juga dalam penelitian Hatzidimitriadou (2002) dalam Budd, M. (2004) menunjukkan bahwa anggota Self Help Group merasa lebih diberdayakan melalui peran mereka dalam kelompok mereka. Pemberdayaan ini bekerja pada tingkat individu tetapi juga beroperasi pada tingkat kolektif dengan anggota kelompok dalam beberapa jenis kelompok merasa lebih mengendalikan hidup mereka melalui aktivisme komunitas. Anggota Self Help Group merasa bahwa mereka memiliki kekuatan aktual atas perubahan sosial sedangkan pengguna layanan kesehatan mental umumnya dianggap sebagai kelompok yang tidak berdaya tanpa kekuatan masyarakat. Penelitian ini menunjukkan bahwa menjadi bagian dari Self Help Group dapat membuat orang tidak hanya merasa lebih baik secara individual tetapi juga secara sosial termasuk dengan kekuatan komunitas yang lebih besar.

Munn-Giddings dan Borkman (2004) juga menggambarkan manfaat kolektif dari menjadi anggota Self Help Group membuat pandangan dunia yang lebih luas; perspektif dan mobilisasi kolektif untuk perubahan sosial atau inovasi layanan; peluang untuk memengaruhi layanan; kritik terhadap praktik profesional; hubungan inovatif dengan sistem kesehatan mental; cara alternatif untuk mendapatkan bantuan dan dekonstruksi diagnosis atau kondisi medis. Manfaat yang paling sering disebutkan anggota dalam Self Help Group adalah berkurangnya isolasi; peningkatan harga diri; peningkatan kepercayaan diri; penerimaan informasi dan dukungan praktis; merasa diterima dan mempelajari keterampilan baru dan strategi koping, 
Sedangkan dalam penelitian Clarke dan Smith (2003 dalam Budd, M. (2004) mereka menggambarkan individu merasa lebih baik tentang diri mereka sendiri dan mendapatkan harga diri karena bantuan yang mereka dapat berikan kepada orang lain. Dalam Roberts et al (1990) dalam Budd, M (2004) mereka menggambarkan prinsip 'terapi helper' yang menjelaskan proses di mana membantu orang lain memiliki efek terapeutik bagi diri sendiri. Self Help Group memberikan peluang bagi individu yang kemampuan dan kekuatannya sering hilang atau tidak diberdayakan untuk menggunakan kekuatan dan kemampuan mereka dan mengambil peran dan tanggung jawab baru dalam lingkungan yang aman.

Penelitian Roberts et al (1990) dalam Budd, M. (2004) memberikan dukungan empiris untuk prinsip 'terapi helper' dengan menunjukkan bahwa peserta dalam penelitian mereka menunjukkan peningkatan pada skala yang mereka gunakan untuk menunjukkan fungsi psikologis dan sosial. Hal ini juga sejalan dengan pernyataan Clarke dan Smith, 2004 dalam Budd, M. (2004) menyatakan tentang anggota Self Help Group merasa lebih baik tentang diri mereka sendiri karena keterampilan mereka diakui, mereka adalah peserta aktif dalam kelompok mereka daripada penerima layanan, dan juga melalui menawarkan bantuan kepada seseorang yang membutuhkannya juga menegaskan nilai mereka, karena membuat mereka merasa berharga dan diinginkan (Roberts et al, 1990 dalam Budd, M. 2004).

Wikipidia (2018) menyatakan bahwa Self Help Group merupakan kelompok asosiasi sukarela dari orangorang yang memiliki keinginan yang sama untuk mengatasi penyakit mental atau meningkatkan tingkat kesejahteraan kognitif atau emosional, dikarenakan seperti yang dinyatakan dalam penelitian Moeller, Michael L.,(1999) dalam Wikipidia (2018) bahwa keanggotaan dalam Self Help Group memiliki hak yang sama, setiap anggota bertanggung jawab hanya untuk diri mereka sendiri, setiap grup bersifat otonom, semua orang menghadiri kelompok karena masalah mereka sendiri, apapun yang dibicarakan dalam kelompok tetap menjadi rahasia, dan partisipasi tidak dikenai biaya, penekanan mereka pada proses psikososial, dan pemahaman yang dimiliki oleh orang-orang dengan penyakit mental yang sama atau serupa.

Dean, Stanley R. (1971) dalam Wikipidia (2018) yang menyatakan bahwa pembelajaran interpersonal, yang dilakukan melalui proses seperti umpan balik dan konfrontasi, umumnya tidak ditekankan dalam Self Help Group

Demikian juga dalam proses Self Help Group yang paling penting adalah proses yang memenuhi kebutuhan pribadi dan sosial dalam lingkungan yang aman dan sederhana. Demikian juga dari hasil identifikasi para peneliti menyatakan tidak terbatas juga: penerimaan, latihan perilaku, mengubah anggota perspektif dari diri mereka sendiri, mengubah perspektif anggota dunia, katarsis, kepunahan /pematian, pemodelan peran, belajar strategi koping baru, saling peneguhan, pengaturan tujuan pribadi, menanamkan harapan, pembenaran/ justification, normalisasi, penguatan positif, mengurangi isolasi sosial, mengurangi stigma, keterbukaan diri , berbagi/sharing, dan menunjukkan empati (Solomon, Phyllis (2004), Davidson dkk (1999), Moeller, Michael L. 
(1999).Wollert, dkk (1982), Dean, Stanley R. (1971), Powell, dkk (2000), Sargent, dkk (2002) dalam Wikipidia (2018)).

Dengan demikian Self Help Group dapat meningkatkan mekanisme koping pasien, dalam kelompok pasien belajar strategi koping baru menemukan langsung pengalaman nyata yang diperoleh bisa langsung dirasakan pasien mengubah dalam perspektif diri mereka sendiri, sebagai latihan perilaku, penyesuaian dan proses pemulihan sehingga dapat memperdayakan kemampuan dan kekuatannya untuk menggunakan kekuatan dan kemampuan dirinya mengambil peran dan tanggung jawabnya.

Harapan kedepan peneliti seperti yang diungkapkan oleh Powell, dkk (2010) bahwa sifat dari kelompokkelompok Self Help Group ini, diharapkan SHG dapat membantu membiayai biaya perawatan kesehatan mental dan penerapannya ke dalam sistem kesehatan mental yang ada dan dapat membantu menyediakan perawatan bagi lebih banyak populasi yang sakit jiwa.

\section{KESIMPULAN DAN SARAN}

Kesimpulan bahwa Self Help Group yang digunakan untuk intervensi efektif untuk meningkatkan mekanisme koping, ditunjukan terdapat perbedaan secara statistik signifikan $\mathrm{p}=0,000 \quad(\mathrm{p}$ value $<\alpha 0,05)$ antara kelompok intervensi dan kontrol, demikian juga berpeluang meningkatkan mekanisme koping pasien sebesar 20,1\% dan dapat meningkatkan nilai mekanisme koping sebesar 4.909 poin lebih tinggi dari pada responden yang tidak mendapatkan intervensi Self Help Group

Disarankan Self Help Group digunakan sebagai intervensi kelompok keperawatan jiwa dalam merawat pasien gangguan jiwa dan dipakai sebagai salah satu pedoman dalam memberikan asuhan keperawatan pada pasien gangguan jiwa

\section{DAFTAR RUJUKAN}

Anderson ET. And Mc Farlane, J, 2000. Comunity as pasthner theory and practice in nursing. Philadelphia:Lippincott.

Budd, M. 2004. Self-help groups for individuals who experience mental distress: Proceedings of a self-help group members' symposium and a review of selected literature. https://www.mentalhealth.org.uk/ sites/.../self_help_groups.p...

\section{Good Therapy .2018 Coping- Mechanisms. \\ https://www.goodtherapy.org/blo g/psychpedia/coping- mechanisms}

Dep Kes RI. 2013. Riset Kesehatan Dasar.

http://www.depkes.go.id/resource s/download/general/Hasil\%20Ris kesdas\%202013.pdf

Dep Kes RI. 2016. Peran keluarga dukung dalam kesehatan jiwa masayarakat.

http://www.depkes.go.id/article/p rint/16100700005/peran-

keluarga-dukung-kesehatan-jiwamasyarakat.html

Dep Kes RI. 2018. Riset Kesehatan Dasar.

http://www.depkes.go.id/resource s/download/infoterkin/materi_rak orpop_2018/Hasil\%20Riskesdas $\% 202018 . p d f$

Hastono, S.P. 2007, Analisis data kesehatan. Tidak dipublikasikan, Depok. 
Keliat, B. A. 2003. Pemberdayaan klien dan keluarga dalam perawatan klien skizofrenia dengan perilaku kekerasan di Rumah Sakit Jiwa Pusat Bogor, Disertasi Program Pascasarjana FKM UI. Tidak dipublikasikan.

Kozier ,B., J.,. 2004 Fundamentals of nursing consepts proses and practice.

Notoatmodjo, S. 2010. Metodologi Penelitian Kesehatan. Jakarta: Rineka Cipta

Budd, M. 2004. Self-help groups for individuals who experience mental distress: Proceedings of a self-help group members' symposium and a review of selected literature. https://www.mentalhealth.org.uk/s ites/.../self_help_groups.p...

Powell, Thomas J.; Perron, Brian E. (2010), "The Contribution of Self-Help Groups to the Mental Health/Substance Use Services System" , Mental Health SelfHelp, Springer New York,

Rasmun. 2004. Stres koping dan adaptasi. Jakarta : CV Agung Seto

RSJD Surakarta. 2013 ProfilRumahSakitJiwa Daerah Surakart. RSJD Surakarta.

RSJD Surakarta. 2017. ProfilRumahSakitJiwa Daerah Surakart. RSJD Surakarta.

Sugiyono. 2010. Metobe Penelitian Administrasi, Dilengkapindengan Metode R\&D. Bandung: Alfabeta.

Sulistyowati, E.C., Patriyani, R.E.H. and Insiyah. 2017. The Effect of Spiritual Emotional Freedom Technique to Increase Self
Esteem of Schizophrenia in Mental Hospital Surakarta. Fakultas Keperawatan Universitas Airlangga : The Proceeding of 8th International Nursing Conference: Education, Practice and Research Development In Nursing

Stuart and Sunden. (2007). Keperawatan jiwa, EGC,JakartaStuart, G.W., and Laraia. 2005. Principles and practice of psyhiatric nursing.(7"' ed.). St. Louis : Mosby Year B.

Townsend, M. 2005. Essentials of psychiatric mental health nursing. (3 d ed) Philadelphia, F.A.Davis Company

Videbeek, S.L. 2008. Psychiatric mental health nursing.(3r $\mathrm{d}$ edition). Philadhelpia: Lippincott Williams \& Wilkin

WHO. 2017. WHO. 2017 Mental disorders

https://www.who.int/mental_heal th/management/en

WHO.2018. WHO 2018 Mental disorders

https://www.who.int/newsroom/factsheets/detail/mentaldisorders

Wikipedia 2018. Self Help Group for Mental

Heath.https://en.wikipedia.org/wi ki/Self-help groups for mental health

Zachariades, F. K. (2000).Coping with health-related problems and psychological distress amongst older adult hospital patients. Retrieved from https://ro.ecu.edu.au/theses/1392 